\title{
Do Spa Visits Improve Health: Evidence From German Micro Data
}

\author{
Jonathan Klick ${ }^{\mathrm{a}}$ and Thomas Stratmann ${ }^{\mathrm{b}}$ \\ ${ }^{a}$ Florida State University College of Law. \\ ${ }^{\mathrm{b}}$ Department of Economics, George Mason University, 1D3 Carow Hall, Fairfax, VA 22030, U.S.A. \\ E-mail: tstratma@gmu.edu
}

The health benefits of spas have been hypothesized for centuries. If this hypothesis is correct, spa therapy offers a low cost alternative to more expensive and potentially more invasive medical treatments for ailments such as back pain and arthritis. We use individual-level panel data to isolate the effect of spa therapy on missed workdays and hospital visits in Germany. Simple correlations suggest a self-selection bias - spa visits are associated with increased absenteeism and hospitalization. However, when we exploit the longitudinal nature of the data, we find that spa therapy leads to a statistically significant reduction in both absenteeism and hospitalization, though it is not clear if these health benefits justify the cost of spa therapy.

Eastern Economic Journal (2008) 0, 000-000. doi:10.1057/palgrave.eej.9050038

\section{Keywords: I; I; !; I}

\section{JEL: I; I; I; !}

\section{INTRODUCTION}

Spa therapy dates at least to classical times when Hippocrates proposed that all disease was the result of imbalances of bodily fluids. Spas remained popular until the fall of the Roman Empire, dropping into disfavor during the Dark and Middle Ages. Although they did not regain their universal popularity, spa therapy was increasingly prescribed under medical direction during the Renaissance [Porter 1990]. While British spas tended to emphasize pleasure and leisure in the 20th century, spas that focused on serious medical treatments proliferated in continental Europe. Acknowledgment of the medical benefits of spa therapy by many rheumatologists and dermatologists coupled with coverage by many government health systems placed spa therapy in the mainstream of medical treatments [van Tubergen and van der Linden 2002].

Despite the long history of spa therapy, there is relatively little in the way of empirical evidence that overcomes selection effects and evaluates the causal benefits of spa treatment. If the benefits of spa treatments are little more than folklore or ephemeral placebo effects, subsidizing spa therapy through public or private insurance plans is socially wasteful. However, if spa therapy does produce significant medical benefits, governments and insurers might consider expanding coverage to counteract the rising cost of conventional healthcare, while providing patients with effective, non-invasive alternatives to the existing standard of care.

In this study we examine whether spa treatments reduce workday loss and hospital stays, and whether the benefits of these treatments are sufficiently large to warrant subsidization of these treatments. We propose a panel data design to isolate

Disk used

Pages: $1-11$
Despatch Date: 19/10/2007

Op: HNM Ed: Prasad 
the health effects of spa treatments with respect to missed workdays and hospital visits.

Our use of a large-scale micro data set allows us to examine thousands of individuals, and the longitudinal nature of the data allows us to control for selfselection biases, isolating any causal effect of spa treatments on health outcomes. By exploiting the panel structure of our data, we can effectively control for selection effects via individual fixed effects. Further, by focusing on revealed measures of healthfulness, workplace absenteeism, and hospital visits, we mitigate the subjective nature of pain measures.

Using data from the German Socio-Economic Panel Study (GSOEP), we find strong evidence of self-selection in the decision to undertake spa therapy. That is, if we ignore the longitudinal nature of the data and simply examine cross-sectional correlations, we find that individuals who visit a spa in a given year exhibit significantly more absenteeism and have higher hospitalization rates during the following year. However, if we control for self-selection by including individual-level fixed effects, and examine the within-individual variation in absenteeism and hospitalization, our estimates suggest that spa therapy significantly improves health. These health, labor market, and medical expenditure benefits from spa therapy suggest that public and private insurers might benefit from expanding coverage of spa treatments.

\section{EXISTING EVIDENCE OF THE EFFICACY OF SPA TREATMENTS}

A number of theories have been proposed regarding how spa therapy ${ }^{1}$ positively affects health. Practitioners of spa therapy have suggested that spa waters may detoxify a person's blood, improve blood circulation, immunities, or digestion. The preferred causal mechanism often invokes the observation that applying warmth to the skin causes blood vessels to expand, bringing blood to the body's surface and relaxing muscles.

In addition to the long tradition of using spas for medicinal effects, a number of public and private insurers have begun to investigate their use as an alternative to more expensive medical treatments. In 1996, the Italian Ministry of Health undertook a large-scale investigation of the efficacy of Italian spas for a host of medical problems through its Project Naiade with the expressed goal of determining the extent to which Italy's National Health Service should subsidize spa treatments. Early research using Naiade data suggests that spa treatments can lead to significant benefits, including a reduction in missed workdays and hospital visits [Coccheri et al. 2002; Fioravanti et al. 2003]. Though the Naiade studies are large in scope since they examine the effects of every spa in Italy and focus on large samples of patients, the early published work has not made use of control groups, leaving open the possibility of self-selection effects. Lack of sufficient control groups limits the ability to draw causal inferences from many of the studies published on the efficacy of European spas [Verhagen et al. 1997].

A number of studies examine the effects of different spa therapies on particular maladies but do not allow the researcher to identify a baseline effect of any spa treatment relative to no-spa treatment. Those studies examine only differentials among competing treatments [Wigler et al. 1995; Leibetseder et al. 2004]. Another set of studies has documented spa-induced improvements in subjective well-being [Strauss-Blasche et al. 2000], blood pressure [Ekmekcioglu et al. 2000], glucose levels 
[Ohtsuka et al. 1996], and lower back pain [Konrad et al. 1992], but these studies lack strong control groups.

The few existing papers with strong control groups and methodological designs also suggest that the health benefits of spa therapy are significant. Constant et al. [1995] find that patients with chronic lower back pain who receive both spa and drug therapy exhibit lower pain duration and intensity and consume fewer analgesics than do patients in a drug therapy only control group. Nguyen et al. [1997] find similar effects for patients with back, hip, or knee pain who receive spa therapy and drug therapy, relative to a no-spa control group. Szucs et al. [1989] also document improvements in knee pain for individuals undergoing spa therapy in Hungary relative to control groups.

However, one of the best designed studies in this field failed to find significant health benefits from spa therapy. Exploiting the fact that France's national health insurance system covers spa therapy in some cases, Allard et al. [1998] were able to have two separate well-designed control groups. Specifically, they studied the 220 patients who filed applications for spa therapy in the first 6 months of 1994. Seventy-two individuals in the pool qualified for and were provided with covered spa treatments. Of those who did not qualify, individuals were randomly assigned to a spa therapy group and a no-spa therapy group. Among the qualified group, no improvements were observed in terms of health care expenditures for individuals who had visited spas prior to the study. For first time visitors, the only improvements occurred among those with rheumatological problems. Among the non-qualified pool, there were no discernible differences in health care costs between the spa and no-spa groups, prompting the authors to suggest that national health insurance policies be re-evaluated with regard to the coverage of spa therapy.

Recently, Ernst and Pittler [1998] reviewed existing randomized studies on the effectiveness of spa treatments. After examining all studies they conclude that the evidence with respect to the benefits of spa treatments is inconclusive and that the sum of current studies neither proves nor disproves that spa treatments are beneficial.

As indicated by this review of the literature, while there is substantial traditional support for the value of spa therapy, scientific evidence is limited at best with respect to the efficacy, much less the efficiency, of spa therapy. Most studies have some methodological drawbacks and virtually all of the studies suffer from small sample sizes that do not allow researchers to control for other variables that might be important in determining health outcomes. Although randomized studies have some drawbacks, our study that is based on longitudinal data, based on surveys, also exhibits limitations. For example, randomization procedures in controlled trials do not have the selection bias issues that are inherent in longitudinal studies that are based on surveys. We will address this selection bias in our data analysis.

\section{METHODS}

About 90 percent of the German population is covered by the German statutory health insurance (Gesetzliche Krankenversicherung). Benefits to insured individuals are more or less the same across all insured individuals. Membership to the German health insurance is mandatory for individuals with earnings below a certain cut-off value (approximately $\$ 3,300$ in monthly gross earnings in 2000). The insurance premium is paid by payroll taxes and the employer and employee pay an equal share 
of the tax. Thus, the insurance premium is not determined by individuals' health status, age, or gender. In contrast, private insurance, obtained by some of those with earnings above the wage cut-off value, will base the premiums on the health characteristics of the insured. Both, private and public insurance offer a spa treatment benefit.

Germany has both inpatient and outpatient spa treatments. The spa variable in our data set measures whether an individual had an inpatient spa treatment. Thus, we will focus on inpatient, not outpatient spa treatment. ${ }^{2}$ Originally many spas in Germany were built around mineral springs, but nowadays, many spas that are attended by individuals for medical reasons are often not located at mineral springs, but are treatment facilities, where individuals engage in medical treatments and physical therapy prescribed by physicians. In the latter type of facilities a doctor examines the patient at the beginning and prescribes physical therapy exercises to increase, for example, range of motion, or to encourage rehabilitation after a physical trauma. Medication may also be prescribed.

Individuals insured by the statutory health insurance apply to the insurance company for spa treatment. One of the application requirements is a certificate from a medical doctor, indicating that spa treatment is "necessary" for the continued health of the individual. If the individual has this certificate, a spa treatment is granted, subject to the qualifications explained below.

In 1997, the maximum time allowed for spa treatments, if it was to be covered by insurance, was reduced from 4 to 3 weeks, and spa treatments were limited to one treatment within 4 years. Since our data range from 1987 to 1997 individuals could qualify for up to a 4-week spa treatment. In 2000, more exceptions were granted from the maximum stay of 3 weeks, than were already granted in the 1997 law. Insurance pays the full cost of spa services subject to a co-payment of 10 Euro per day. Prior to 1997, there was no co-payment required.

The GSOEP offers a rich longitudinal data set that contains a wealth of information on nearly 24,000 individuals since 1984. Of particular interest for analyzing the efficacy of spa therapy, in 1987, the GSOEP started asking individuals if they visited a health spa (inpatient treatment) during the previous year. The question was last included in the survey in 1997. Combining the answers from that question with data on health attributes, such as missed workdays and hospitalization measures, we can examine the relationship between spa therapy and physical well-being, while controlling for other potentially important variables that affect health.

Our data are annual data on individuals from 1987 to 1997. In this data set, we can follow employed individuals over time and, because of our estimation strategy that will allow us to control for selection effects, we will use only observations where we have at least two observations for the individual.

Given the potential for self-selection which has plagued some of the existing medical studies of spa therapy, a very useful aspect of the GSOEP is its longitudinal nature. That is, we can use the repeated observations on a given individual to control for idiosyncratic unobservable attributes that are likely to help determine that individual's health. By focusing on this within-individual variation, we can mitigate any self-selection bias that exists when simply correlating spa use and health.

Much of the work that examines the economics of health and uses the GSOEP data set has not exploited the panel structure of this data set (see, e.g., Pohlmeier and Ulrich 1995]. One exception includes Riphahn et al. [2003] who examine the determinants of health care demand using GSOEP panel data. 
Spa visits are not randomly distributed across the population. Spa visits and health metrics are jointly determined since individuals with worse health are more likely to attend spas. This joint determination implies that a simple correlation will not uncover a causal effect of changes in health due to spa visits. In this paper our metric of health status is lost workdays and the number of days in a hospital. Since one of our metrics is lost workdays, another form of simultaneity is potentially harmful to our analysis. If individuals who wish to consume more leisure are also prone to missing work and eager to attend a health spa, then the point estimate on spa treatments is biased toward a positive correlation.

Before estimating regressions that control for the simultaneous determination of spa visits and work loss das and hospital stays, we will first run regression models that do not control for the simultaneity. This will allow us to assess the degree of self-selection when we compare these estimates to the estimates that control for selfselection. Since our dependent variable is the number of hospital days and the number of missed workdays, a model that explicitly recognizes that we have count data, the negative binomial model, is preferred over the OLS model. ${ }^{3}$ However, we will also estimate the regressions with OLS, in order to assess the robustness of the estimates. Our empirical models that do not correct for selection effects are

$$
\begin{aligned}
\text { Absent }_{i t} & =\alpha+\delta \text { spa }_{i t-1}+\beta \Theta+\tau_{t}+\varepsilon_{i t} \\
\text { Hospital }_{i t} & =\pi+\phi \operatorname{spa}_{i t-1}+\varphi \chi+v_{t}+\varepsilon_{i t}
\end{aligned}
$$

In these regressions, we examine the effect of a previous year's visit to a health spa on the current year's missed work days and hospitalization, controlling for year fixed effects to control for economy wide influences on health, as well as a vector of individual-specific attributes such as income, age, subjective health measure, and employment characteristics such as firm size and hours worked.

To control for unobservable variation in that data, we propose regression models that control for individual fixed effects ${ }^{4}$ as indicated below:

$$
\begin{aligned}
\text { Absent }_{i t} & =\alpha+\delta \text { spa }_{i t-1}+\beta \Theta+\tau_{t}+\lambda_{i}+\varepsilon_{i t} \\
\text { Hospital }_{i t} & =\pi+\phi \text { spa }_{i t-1}+\varphi \chi+v_{t}+\omega_{i}+\varepsilon_{i t}
\end{aligned}
$$

As discussed previously, we will estimate these fixed effects models using OLS and the negative binomial regression models. Fixed effects capture time invariant characteristics and thereby we control for unobserved variables that are constant over time and that lead a person to take more or less spa treatments. Individual fixed effects, however, do not capture any time-variant unobserved characteristics. This could be a problem with a long time series. If unobserved characteristics that influence the likelihood of spa treatments and work day loss change over time, the estimates will still contain some bias.

\section{RESULTS AND DISCUSSION}

Descriptive statistics for all variables are presented in Table 1. The GSOEP data show that approximately 10 percent of the nearly 30,000 usable observations indicate that the individual visited a spa during the previous year. Workers report ill for about 20 days in a year and are hospitalized for roughly 1.5 days per year. Our hospitalization sample is much smaller than our work loss sample. This is because 
Table 1 Descriptive statistics

\begin{tabular}{llrrr}
\hline Variable & Description & Mean & Stand. Dev. & $n$ \\
\hline Absent & Number of days out sick during year $t$ & 20.640 & 33.710 & 29,985 \\
Hospitalization & Days spent in hospital during year $t$ & 1.387 & 1.566 & 4,537 \\
Lag spa & $=1$ if individual visited a health spa during year $t-1$ & 0.101 & 0.301 & 29,985 \\
Health & Satisfaction with health on a 0 (Low) to 10 (High) Scale & 6.800 & 2.115 & 29,938 \\
Age & Age at time of survey in year $t$ & 37.452 & 11.609 & 29,985 \\
Income & Gross monthly income in year $t-1$ 1, & $3,400.699$ & $1,964.334$ & 29,985 \\
Firm size & Number of workers employer has [categorical: & 2.930 & 1.019 & 14,103 \\
& l(0 to 19); 2 (20 to 199); 3 (200 to 1,999); 4 (2000 +)] & & & \\
Hours worked & Average number of hours worked per week in year $t$ & 39.713 & 9.541 & 29,116 \\
\hline
\end{tabular}

the hospitalization data are missing for most respondents (i.e., we do not know if the person was hospitalized or not). In our regressions, we include all observations for which data on whether a person has been hospitalized are available.

Table 2 shows the estimation results. As the self-selection hypothesis implies, we do find a strong positive correlation between spa visits and absenteeism and hospitalization. The OLS models suggest that individuals visiting a spa in year $t-1$, miss about 5 extra days of work in year $t$, which is a relative change of about 25 percent. The result is statistically significant at the 1 percent level. The negative binomial models tell much the same story, suggesting that absenteeism increases by about 20 percent when an individual visits a spa during the previous year and the coefficients are statistically significant at the 1 percent level.

For the covariates, we find quadratic relationships for both age and income, regardless of the model specification. As people age, they miss less work, but at some point the relationship reverses itself with the very old missing more work. For income, individuals are absent less often as their income increases, but at relatively high incomes, people start to miss work more frequently. Intuitively, the results show that people miss less work when their subjective health evaluation is good. ${ }^{5}$

Lastly, it seems that individuals who work at larger firms are more apt to miss work, and those working especially long work weeks miss more days as well. Both of the coefficients firm size and hours worked are statistically significant at the 1 percent level. One possible explanation for this result is that a worker's absence will be less noticeable at a larger firm, all things equal. Also, larger firms tend to be manufacturing firms and work in those firms may be inherently more hazardous than work in white-collar occupations. One explanation for the finding that people with longer workdays are more likely to incur workday loss is that individuals working longer weeks might find it more difficult to recuperate on the job when an injury or illness sets in. 6,7

The results for the hospitalization measure are complementary to our workday loss results. We find a positive relationship or no relationship between spa visits and hospitalization in the OLS regressions. The coefficients are not statistically significant, though this is likely due to the smaller sample size available for the hospitalization measure. For the negative binomial regressions, we again find a positive relationship between previous year spa visits and current hospitalization in the specification that does not include firm size and hours worked. The point estimate on spa visits is statistically significant at the 5 percent level. In the 
Table 2 Naive relationship between Spa visits and health outcomes (standard errors below coefficients)

\begin{tabular}{|c|c|c|c|c|c|c|c|c|}
\hline \multirow[b]{3}{*}{ Lag spa } & \multicolumn{4}{|c|}{ Absent } & \multicolumn{4}{|c|}{ Hospitalization } \\
\hline & \multicolumn{2}{|c|}{ OLS model } & \multicolumn{2}{|c|}{$\begin{array}{c}\text { Negative } \\
\text { binomial model }\end{array}$} & \multicolumn{2}{|c|}{ OLS model } & \multicolumn{2}{|c|}{$\begin{array}{c}\text { Negative } \\
\text { binomial model }\end{array}$} \\
\hline & $\begin{array}{c}5.378 \\
(0.885)\end{array}$ & $\begin{array}{c}4.525 \\
(1.420)\end{array}$ & $\begin{array}{c}0.199 \\
(0.025)\end{array}$ & $\begin{array}{c}0.176 \\
(0.043)\end{array}$ & $\begin{array}{c}0.162 \\
(0.090)\end{array}$ & $\begin{array}{c}-0.005 \\
(0.146)\end{array}$ & $\begin{array}{c}0.110 \\
(0.050)\end{array}$ & $\begin{array}{c}0.000 \\
(0.082)\end{array}$ \\
\hline Health & $\begin{array}{c}-3.273 \\
(0.093)\end{array}$ & $\begin{array}{c}-2.985 \\
(0.135)\end{array}$ & $\begin{array}{c}-0.124 \\
(0.003)\end{array}$ & $\begin{array}{r}-0.119 \\
(0.004)\end{array}$ & $\begin{array}{c}-0.004 \\
(0.010)\end{array}$ & $\begin{array}{c}-0.004 \\
(0.016)\end{array}$ & $\begin{array}{c}-0.003 \\
(0.006)\end{array}$ & $\begin{array}{c}-0.003 \\
(0.009)\end{array}$ \\
\hline Age & $\begin{array}{c}-0.708 \\
(0.113)\end{array}$ & $\begin{array}{c}-0.685 \\
(0.165)\end{array}$ & $\begin{array}{c}-0.022 \\
(0.003)\end{array}$ & $\begin{array}{r}-0.024 \\
(0.005)\end{array}$ & $\begin{array}{c}-0.010 \\
(0.013)\end{array}$ & $\begin{array}{c}0.001 \\
(0.020)\end{array}$ & $\begin{array}{c}-0.006 \\
(0.007)\end{array}$ & $\begin{array}{c}0.000 \\
(0.011)\end{array}$ \\
\hline $\mathrm{Age}^{2}$ & $\begin{array}{c}0.014 \\
(0.001)\end{array}$ & $\begin{array}{c}0.014 \\
(0.002)\end{array}$ & $\begin{array}{c}0.005 \\
(0.000)\end{array}$ & $\begin{array}{c}0.001 \\
(0.000)\end{array}$ & $\begin{array}{c}0.002 \\
(0.002)\end{array}$ & $\begin{array}{c}0.000 \\
(0.003)\end{array}$ & $\begin{array}{c}0.001 \\
(0.001)\end{array}$ & $\begin{array}{c}0.000 \\
(0.001)\end{array}$ \\
\hline Income & $\begin{array}{c}-0.001 \\
(0.000)\end{array}$ & $\begin{array}{c}-0.002 \\
(0.000)\end{array}$ & $\begin{array}{c}-0.007 \\
(0.000)\end{array}$ & $\begin{array}{c}-0.001 \\
(0.000)\end{array}$ & $\begin{array}{c}-0.003 \\
(0.002)\end{array}$ & $\begin{array}{c}-0.009 \\
(0.005)\end{array}$ & $\begin{array}{c}-0.002 \\
(0.001)\end{array}$ & $\begin{array}{r}-0.006 \\
(0.003)\end{array}$ \\
\hline Income $^{2}$ & $\begin{array}{c}0.011 \\
(0.005)\end{array}$ & $\begin{array}{c}0.003 \\
(0.002)\end{array}$ & $\begin{array}{c}0.004 \\
(0.002)\end{array}$ & $\begin{array}{c}0.001 \\
(0.000)\end{array}$ & $\begin{array}{c}0.007 \\
(0.009)\end{array}$ & $\begin{array}{c}0.005 \\
(0.004)\end{array}$ & $\begin{array}{c}0.005 \\
(0.005)\end{array}$ & $\begin{array}{c}0.003 \\
(0.002)\end{array}$ \\
\hline Firm size & - & $\begin{array}{c}0.907 \\
(0.278)\end{array}$ & - & $\begin{array}{c}0.036 \\
(0.009)\end{array}$ & - & $\begin{array}{c}0.020 \\
(0.035)\end{array}$ & & $\begin{array}{c}0.014 \\
(0.020)\end{array}$ \\
\hline Hours worked & - & $\begin{array}{c}0.194 \\
(0.030)\end{array}$ & - & $\begin{array}{c}0.011 \\
(0.001)\end{array}$ & - & $\begin{array}{c}0.004 \\
(0.004)\end{array}$ & & $\begin{array}{c}0.003 \\
(0.002)\end{array}$ \\
\hline$n$ & 29,938 & 13,670 & 29,938 & 13,670 & 4,534 & 2,084 & 4,534 & 2,084 \\
\hline$R^{2}$ & 0.079 & 0.074 & - & - & 0.006 & 0.008 & - & - \\
\hline Log likelihood & - & - & $-118,706$ & $-53,597$ & - & - & $-6,393$ & $-2,960$ \\
\hline
\end{tabular}

Note: All data come from the German Socio-Economic Panel Study. The absent metric measures the number of missed workdays in year $t$. Lag spa indicates whether or not the individual visited a health spa in year $t-1$. Coefficients and standard errors for age, age $^{2}$, income, and income ${ }^{2}$ have been scaled for presentation when necessary. All regressions include year fixed effects.

specification that includes firm size and hours worked, we find no relationship between spa visits and hospitalization.

So far, the discussed results do not stem from a model that controls for the simultaneity bias that exists between health and the choice to visit a spa. To account for this joint determination, we exploit the panel nature of the GSOEP data. While we do not observe all variables for all individuals over the 10 years for which we have observations on spa visits, we have multiple observations for 6,769 individuals. $^{8}$

Once we control for idiosyncratic differences in this manner, the relationship between spa visits and our health metrics reverses. As presented in Table 3, we find a negative relationship between previous year spa visits and current year absenteeism. The OLS results indicate that a spa visit reduces missed workdays in the following year by between $1.7(P=0.08)$ and $5.5(P=0.00)$ days, a relative effect of between 8 and 27 percent. The negative binomial models suggest a reduction in missed workdays of between $7(P=0.00)$ and $10(P=0.02)$ percent. The relationship between most of the other covariates and missed workdays is consistent with the results in Table 2, though the statistical significance of the coefficients is sensitive to the specification.

We observe a reversal in signs for the spa coefficients in the hospitalization regressions as well. The OLS regressions indicate that a spa visit during the previous year reduces the number of hospital visits during the current year by between 0.20 $(P=0.16)$ and $1.4(P=0.00)$. The point estimates for the negative binomial models 
Table 3 Relationship between spa visits and health outcomes controlling for self-selection (standard errors below coefficients)

\begin{tabular}{|c|c|c|c|c|c|c|c|c|}
\hline \multirow[b]{3}{*}{ Lag spa } & \multicolumn{4}{|c|}{ Absent } & \multicolumn{4}{|c|}{ Hospitalization } \\
\hline & \multicolumn{2}{|c|}{ OLS model } & \multicolumn{2}{|c|}{$\begin{array}{c}\text { Negative } \\
\text { binomial model }\end{array}$} & \multicolumn{2}{|c|}{ OLS model } & \multicolumn{2}{|c|}{$\begin{array}{c}\text { Negative } \\
\text { binomial model }\end{array}$} \\
\hline & $\begin{array}{r}-1.653 \\
(0.947)\end{array}$ & $\begin{array}{c}-5.531 \\
(1.763)\end{array}$ & $\begin{array}{r}-0.070 \\
(0.022)\end{array}$ & $\begin{array}{r}-0.100 \\
(0.042)\end{array}$ & $\begin{array}{r}-0.194 \\
(0.137)\end{array}$ & $\begin{array}{r}-1.410 \\
(0.353)\end{array}$ & $\begin{array}{r}-0.124 \\
(0.077)\end{array}$ & $\begin{array}{r}-0.574 \\
(0.168)\end{array}$ \\
\hline Health & $\begin{array}{c}-1.981 \\
(0.133)\end{array}$ & $\begin{array}{c}-1.591 \\
(0.226)\end{array}$ & $\begin{array}{c}-0.024 \\
(0.003)\end{array}$ & $\begin{array}{r}-0.019 \\
(0.005)\end{array}$ & $\begin{array}{c}0.001 \\
(0.023)\end{array}$ & $\begin{array}{c}0.019 \\
(0.061)\end{array}$ & $\begin{array}{r}-0.007 \\
(0.013)\end{array}$ & $\begin{array}{c}0.012 \\
(0.030)\end{array}$ \\
\hline Age & $\begin{array}{c}-1.277 \\
(1.430)\end{array}$ & $\begin{array}{c}1.988 \\
(2.901)\end{array}$ & $\begin{array}{c}-0.063 \\
(0.005)\end{array}$ & $\begin{array}{r}-0.079 \\
(0.009)\end{array}$ & $\begin{array}{c}-0.292 \\
(0.210)\end{array}$ & $\begin{array}{c}-2.492 \\
(2.612)\end{array}$ & $\begin{array}{c}-0.111 \\
(0.054)\end{array}$ & $\begin{array}{r}-0.066 \\
(0.109)\end{array}$ \\
\hline $\mathrm{Age}^{2}$ & $\begin{array}{c}0.042 \\
(0.003)\end{array}$ & $\begin{array}{c}0.053 \\
(0.007)\end{array}$ & $\begin{array}{c}0.001 \\
(0.000)\end{array}$ & $\begin{array}{c}0.001 \\
(0.000)\end{array}$ & $\begin{array}{c}0.001 \\
(0.001)\end{array}$ & $\begin{array}{r}-0.000 \\
(0.002)\end{array}$ & $\begin{array}{c}0.001 \\
(0.000)\end{array}$ & $\begin{array}{c}0.000 \\
(0.001)\end{array}$ \\
\hline Income & $\begin{array}{r}-0.005 \\
(0.003)\end{array}$ & $\begin{array}{r}-0.007 \\
(0.007)\end{array}$ & $\begin{array}{c}0.001 \\
(0.000)\end{array}$ & $\begin{array}{c}0.002 \\
(0.001)\end{array}$ & $\begin{array}{c}-0.003 \\
(0.008)\end{array}$ & $\begin{array}{c}0.000 \\
(0.003)\end{array}$ & $\begin{array}{r}-0.002 \\
(0.005)\end{array}$ & $\begin{array}{r}0.000 \\
(0.001)\end{array}$ \\
\hline Income $^{2}$ & $\begin{array}{c}0.002 \\
(0.006)\end{array}$ & $\begin{array}{c}0.000 \\
(0.003)\end{array}$ & $\begin{array}{r}-0.004 \\
(0.002)\end{array}$ & $\begin{array}{r}-0.003 \\
(0.008)\end{array}$ & $\begin{array}{c}0.001 \\
(0.004)\end{array}$ & $\begin{array}{r}-0.001 \\
(0.002)\end{array}$ & $\begin{array}{c}0.001 \\
(0.002)\end{array}$ & $\begin{array}{r}-0.006 \\
(0.009)\end{array}$ \\
\hline Firm size & - & $\begin{array}{c}0.203 \\
(0.579)\end{array}$ & - & $\begin{array}{c}0.037 \\
(0.012)\end{array}$ & - & $\begin{array}{l}0.020 \\
(0.170)\end{array}$ & & $\begin{array}{r}0.017 \\
(0.089)\end{array}$ \\
\hline Hours worked & - & $\begin{array}{c}0.044 \\
(0.059)\end{array}$ & - & $\begin{array}{r}-0.001 \\
(0.001)\end{array}$ & - & $\begin{array}{c}0.011 \\
(0.015)\end{array}$ & & $\begin{array}{c}0.006 \\
(0.007)\end{array}$ \\
\hline$n$ & 29,938 & 13,670 & 26,754 & 10,325 & 4,534 & 2,084 & 2,128 & 567 \\
\hline$R^{2}$ & 0.521 & 0.655 & - & - & 0.773 & 0.834 & - & - \\
\hline Log likelihood & - & - & $-68,496$ & $-21,984$ & - & - & $-1,223$ & -294 \\
\hline
\end{tabular}

Note: All data come from the German Socio-Economic Panel Study. The absent metric measures the number of missed workdays in year $t$. Lag spa indicates whether or not the individual visited a health spa in year $t-1$. Coefficients and standard errors for age, age $^{2}$, income, and income ${ }^{2}$ have been scaled for presentation when necessary. The OLS models contain individual dummy variables for each person in the sample; the negative binomial models allow for individual coefficients of dispersion for each person in the sample. All regressions include year fixed effects.

suggest reductions between 12 percent $(P=0.11)$ and 57 percent $(P=0.00),{ }^{9}$ though the specification generating the larger coefficient was estimated on very few $(n=567)$ observations due to missing data on firm size and hours worked.

In some specifications the magnitude of the estimated spa effects differs depending on whether firm size is included or not. This occurs because the firm size variable has many missing observations, and therefore the sample differs between the specification that includes firm size and the specification that does not. To make the sample with firm size comparable to the sample without firm size, we imputed average firm size for those observations, where the size variable was missing. When running regressions with this altered variable, the effect of spas on work loss and hospitalization is very similar to the specifications when firm size was excluded. Therefore, results are robust with respect to the inclusion of firm size.

Although not reported in the tables, we also examined whether there is a treatment effect 2 years after the spa visit. The point estimate on spa visits 2 years after the treatment is about $1 / 3$ the size of the coefficient on the 1 year lag spa visit variable in the count models and smaller in the OLS models.

If the social costs of spa visits are the marginal resources it takes to run the spa and the opportunity cost of going to the spa, and if we assume that the opportunity cost of a spa day is equivalent to the value of a work day, then our estimate indicates that a saving of 5 workdays by visiting a spa are completely offset by a visit of 5 
days. If the resource costs of running the spa are large or if the average spa visit is longer than 1 week, the welfare effects of spas are negative. However this welfare loss may be offset by the decrease in hospitalization if hospitalization is very resource expensive. These considerations suggest that the net benefits of spa visits may be small.

Insurers do not bear the opportunity cost of visiting a spa. Insurers bear the price of a spa visit and gain by lower hospitalization incidences. Since hospitalization incidences are likely to be more expensive than spa visits, there may be a gain to the private insurer of including spa visits as part of the benefits.

\section{CONCLUSION}

Spa therapy has many proponents and a long history to support it; this may be why a number of European private and public insurers cover spa treatments. Potentially, spa treatments represent a cheaper alternative to standard medical treatments for a number of health problems.

Using longitudinal micro data from the GSOEP, we demonstrate that there are statistically significant benefits from spa treatments in terms of lower occupational absenteeism and hospitalization, once we control for the endogeneity of the choice to visit a spa through individual fixed effects. Although these results present credible evidence that there is a causal connection between spa visits and improved health, it is unclear whether the improvements are large enough to justify spa visits on the basis of positive net benefits. Our low estimates imply a reduction in workday losses of between 1 and 2 days in the year after the spa visit, and the largest estimates imply a reduction of 5 work loss days. A typical spa treatment lasts about 2 to 3 weeks or between 10 and 15 working days. This suggests that spa treatments need to have large positive effects on reduced work loss days in subsequent years if treatments are to produce net benefits to the economy. Limited testing suggests that any longer term effects are not large. Although the net economic effects of spa therapy appear to be small, the health improvements generated by spa visits identified in this paper could represent net gains for insurers, suggesting that public and private insurers might be well served by additional research in this area.

\section{Notes}

1 Although there are technical distinctions recognized by some health researchers, we treat spa therapy, balneotherapy, and hydrotherapy as effectively interchangeable.

2 Inpatient treatments provide a much more controlled environment for the patient than outpatient treatments. For example, no alcohol consumption is allowed when an individual receives an inpatient treatment, and the treatment facility also has control over the diet. This is not the case for an outpatient treatment, where the individual receives treatment for only a few hours a day. The inpatient treatment is a much more comprehensive treatment option. During inpatient treatments patients typically have a program to follow from the morning until the evening, with different treatments every hour, including exercise. Unfortunately, we cannot test directly whether the health benefit of an inpatient treatment equals that of a non-spa vacation because we do not have data to construct a specific control group for people taking a non-spa vacation. However, people who took a non-spa vacation are included in our data and are thus part of our control group. The reason that we believe that many vacationers are included in our control group is because in Germany workers often receive over 4 weeks of annual vacation. 
3 Although we do not present the diagnostic statistics, in all negative binomial models, we reject the hypothesis of no overdispersion, which is why we present negative binomial results instead of the corresponding Poisson model results.

4 Strictly speaking, the fixed effect model for the negative binomial regressions allows for individual dispersion coefficients rather than a vector of individual dummy variables, but the intuition is similar to that for the OLS fixed effect model.

5 Income is potentially endogenous, if, for example, workday loss leads to lower productivity and thus income.

6 We added gender and marital status to our OLS regressions and the point estimate on spas was virtually unchanged, although both male and marital status indicators were statistically significant.

7 We view the inclusion of this firm size variable as a robustness check with respect to the specification of the model. Health insurance and spa treatments are regulated at the federal government level, and are not included in compensation packages of most German firms. Thus there is less reason to include firm size effects as there would be in the U.S. context.

8 The average number of observations for each individual is 4 ; the minimum is 2 and the maximum number of observations is 10 .

9 It is appropriate to interpret the coefficients of the negative binomial model as semi-elasticities when the coefficient are small $(\beta<0.1$ or $\beta>-0.1)$, but they need to be transformed for larger values such as that in Table 3. Using $\exp (\beta)-1$ to calculate the semi-elasticity, the elasticities for Table 3, column 3 are lagged spa -0.0117 , age -0.105 , and for the lagged spa variable in Table 3 , column $4-0.437$.

\section{References}

Allard, P., J. Deligne, V. Van Bockstael, and B. Duquesnoy. 1998. Is Spa Therapy Cost-Effective in Rheumatic Disorders. Revue du Rhumatisme (English Edition). 5(3): 173-180.

Coccheri, S., G. Nappi, M. Valenti, F. Di Orio, E. Altobelli, and S. DeLuca. 2002. Changes in the Use of Health Resources by Patients with Chronic Phlebopathies after Thermal Hydrotherapy. Report from the NAIADE Project, a Nation-Wide Survey on Thermal Therapies in Italy. International Angiology, 21(2): 196-200.

Constant, F., J.F. Collin, F. Guillemin, and M. Boulange. 1995. Effectiveness of Spa Therapy in Chronic Low Back Pain: Randomized Clinical Trial. Journal of Rheumatology, 22(7): 1315-1320. , F. Guillemin, J.F. Collin, and M. Boulange. 1998. Use of Spa Therapy to Improve the Quality of Life of Chronic Low Back Pain Patients. Medical Care, 36(9): 1309-1314.

Ekmekcioglu, C., G. Strauss-Blasche, J. Feyertag, N. Klammer, and W. Marktl. 2000. The Effect of Balneotherapy on Ambulatory Blood Pressure. Alternative Therapies in Health and Medicine, 6(6): 4653.

Ernst, E., and M.H. Pittler. 1998. Wie effektiv is die Kur? Eine systematische Übersicht andomisierter Studien. Deutsche Medizinische Wochenzeitschrift, 123: 273-277.

Fioravanti, A., M. Valenti, E. Altobelli, F. Di Orio, G. Nappi, A. Crisanti, L. Cantarini, and R. Marcolongo. 2003. Clinical Efficacy and Cost-Effectiveness Evidence of Spa Therapy in Osteoarthritis. The Results of the 'Naiade' Italian Project. Panminerva Medica, 45(3): 211-217.

Konrad, K., T. Tatrai, A. Hunka, E. Vereckei, and I. Korondi. 1992. Controlled Trial of Balneotherapy in Treatment of Low Back Pain. Annals of the Rheumatic Diseases, 51(6): 820-822.

Leibetseder, V., G. Strauss-Blasche, F. Holzer, W. Marktl, and C. Ekmekcioglu. 2004. Improving Homocysteine Levels Through Balneotherapy: Effects of Sulphur Baths. Clinica Chimica Acta; International Journal of Clinical Chemistry, 343(1-2): 105-111.

Nguyen, M., M. Revel, and M. Dougados. 1997. Prolonged Effects of 3 Week Therapy in a Spa Resort on Lumbar Spine, Knee, and Hip Osteoarthritis: Follow-Up After 6 Months. A Randomized Controlled Trial. British Journal of Rheumatology, 36(1): 77-81.

Ohtsuka, Y., N. Yabunaka, I. Watanabe, H. Noro, and Y. Agishi. 1996. Balneotherapy and Platelet Glutathione Metabolism in Type II Diabetic Patients. International Journal of Biometeorology, 39(3): 156-159.

Pohlmeier, W., and V. Ulrich. 1995. An Econometric Model of the Two-Part Decisionmaking Process in the Demand for Health Care. Journal of Human Resources, 30(2): 339-361.

Porter, Roy. 1990. The Medical History of Waters and Spas. London: Wellcome Institute for the History of Medicine. 
Riphahn, Regina T., Achim Wambach, and Andreas Million. 2003. Incentive Effects in the Demand for Health Care: A Bivariate Panel Count Data Estimation. Journal of Applied Econometrics, 18(4): 87405.

Q2

Stratmann, Thomas. 1999. What Do Medical Services Buy? Effects of Doctor Visits on Work Day Loss. Eastern Economic Journal, 25(1): 1-16.

Strauss-Blasche, G., C. Ekmekcioglu, N. Klammer, and W. Marktl. 2000. The Change of Well-Being Associated with Spa Therapy. Research in Complementary and Natural Classical Medicine, 7(6): 269274.

Strauss-Blasche, G. et al. 2002. Contribution of Individual Spa Therapies in the Treatment of Chronic Pain. The Clinical Journal of Pain, 18: 302-309.

Szucs, L., L. Ratko, T. Lesko, I. Szoor, Gy Genti, and G. Balint. 1989. Double Blind Trial on the Effectiveness of the Puspokladany Thermal Water on Arthrosis of the Knee Joint. Royal Society of Health Journal, 109: 7-9.

Van Tubergen, A., and S. van der Linden. 2002. A Brief History of Spa Therapy. Annals of Rheumatic Diseases, 61: 273-275.

Verhagen, A.P., H.C. de Vet, R.A. de Bie, A.G. Kessels, M. Boers, and P.G. Knipschild. 1997. Taking Baths: The Efficacy of Balneotherapy in Patients with Arthritis. A Systematic Review. Journal of Rheumatology, 24(10): 1964-1971.

Wigler, I., O. Elkayam, D. Paran, and M. Yaron. 1995. Spa Therapy for Gonarthrosis: A Prospective Study. Rheumatology International, 15(2): 65-68.

Zweifel, Peter, and Friedrich Breyer. 1997. Health Economics. New York: Oxford University Press. 